\title{
An Assessment on the Uptake Level of a Fully Integrated Human Resource Information System (HRIS): A Case Study of Midlands State University
}

\author{
Mildred Mahapa ${ }^{1} \&$ Vonai Chirasha ${ }^{1}$ \\ ${ }^{1}$ Human Resource Management Department, Midlands State University, Gweru, Zimbabwe \\ Correspondence: Mildred Mahapa, Human Resource Management Department, Midlands State University, Gweru, \\ Zimbabwe. Tel: 26-377-929-7472/26-371-203-3420. E-mail: mupandarem@msu.ac.zw
}

Received: July 5, 2012 Accepted: July 19, 2012 Online Published: October 18, 2012

doi:10.5539/par.v1n1p121 URL: http://dx.doi.org/10.5539/par.v1n1p121

\begin{abstract}
The research was an assessment on the uptake level of a fully integrated HRIS at Midlands State University in Zimbabwe. The research was aimed at assessing at if the university human resource department has adopted a fully integrated HRIS, the challenges being faced as well as the benefits accrued. A combination of research instruments like interviews and participant observation were used in an effort to elicit as much information as possible which was articulated in detail under research method. A total of six out of a population of seven participated in the research and these were selected using the purposive sampling method. It was discovered that the Human Resourced Department had not adopted a fully integrated HRIS but nevertheless they had incorporated some of its areas (i.e salary administration, advertising, employee personal record) in the current system. The department was still working on having the system fully integrated to incorporate areas like logging in of the employees, the process succession planning, the training, the development that can ensure a cohesive system. The major challenge was that the employees within the human resource department were not fully knowledgeable on how the system works due to the fact that they only have basic ideas and therefore could not implement a fully integrated HRIS. The researchers recommend that more training programmes should be conducted and experts in the area should teach the employees on how the system operates.
\end{abstract}

Keyword: human resource information system

\section{Introduction}

The amount of time and resources spent on maintaining the administrative functions of human resource management is significant. A fully integrated HRIS (i.e. Human Resource Information System) is used for employment actions such as applicant tracking, performance management, attendance, compensation and benefits management, the analysis and scheduling of workforce (Mayhew 2011). HRIS is also defined as interrelated components working together to collect, process and disseminate information to support the decision making, the coordination, control, analyse and visualisation of an organisation's Human Resource Management activities , (Dessler 2008:118). A fully integrated HRIS also combines its functions with all other department for the successful attainment of organisational goals : therefore it does not work in isolation. HRIS basically is a system that lets an individual keep track of all your employees and information about them. It is usually done in a database or more often in a series of interrelated database. The main function of human resource (HR) involves tracking many data points on each employee from personnel history, data, capabilities and experiences to payroll competencies. HR functions and activities are now being redesigned to fully leverage on ICT (i.e. information and communication technology). The underlying assumption in using HRIS is that it can assist HR departments in moving from traditional or manual low impact activities to automated, strategic and high impact activities. Many employers are utilizing their HRIS to supplement the HR's department staff by enabling employers to find answers to common questions they would have asked the HR representative. The use of a fully integrated HRIS is now the backbone of most Universities in well developed countries. However, this is not the case in Zimbabwe most universities due to the fact they linger when it comes to this issue. This is the reason that prompted the researcher to find out really the areas that they have tried to adopt in their HRIS and the challenges they are encountering in trying to implement the system. Midlands State University is the case study that was used in to find out more on the uptake level. The University is State is a public one, financed by the State and is located in the Midlands Province 
in Zimbabwe. The university was founded in 2000 and has a staff complement of 1300 . Having such a number of employees the university is therefore not spared when it comes to the issues of having a fully integrated HRIS.

\section{Literature Review}

According to an article by Toresa and Torres (1998), HRIS can be defined as a software or online solution for the data entry, data tracking and data information needed for the human resources', payroll, management and accounting functions within a business. HRIS helps in managing of the company's most valued asset which is the human resource. Cascio (2003:11) articulated that "technology changes the way we live and work. Information and ideas are essential to new creative economy because every country, company and every individual depends increasingly on knowledge". Information technology (I.T) has switched the world into an information globe that is an era where information forms the lifeblood of an organisation. Accurate and timely information is so vital to any business's sustainability and viability. According to a Journal of Information Technology Management (1995), HRIS got its start in the 1960s and 70s as firms converted to their personnel records from hard copy to punched card form and to computer storage. Mainframe computers located in the firm's information system unit made it possible to produce personnel information much quickly than previously. The benefits of increased speed were short lived due to succession of personnel reporting requirements imposed by government legislation. Government required firms to provide statistics concerning their hiring policies and practices. HRIS was forced upon many firms by requirements imposed by the environment mainly those of the federal government. The responsibility of processing human response data was no longer restricted to the Department of Information Systems, but was also shared by the facility. However HR departments did not attempt to take over all the processing but only implemented certain applications. The applications were typically those that could be performed with the mushrooming selection of prewritten HR software or within the development capabilities of the HR information specialist. Such a situation remains common today; many HR applications are performed in I.T, but an increasingly number of them is being implemented in HR.

In addition HRIS, Aroson (2005) reiterates that, traditionally the use of computerised information system was manifested in bookkeeping and payroll functions. Computerised systems then later penetrated into complex managerial areas ranging from design and management of automated factories to the application of artificial automated factories to the application of artificial intelligence methods to evaluation of proposed mergers and acquisitions. Computer applications have moved beyond transaction processing and monitoring to activities to problem solving and solution applications. Crane and Miner (1995), believe that the reasons for the development of HRIS by many companies include the pressure for social reform, extensive government social programmes however most were fuelled by enlightened self interest budding on government contrast

Having looked at the history of HRIS, it is important at this juncture to note that for HRIS to effectively function it should be viewed from a holistic point of view. The concept of a fully integrated HRIS is linked to systematic thinking or systems thinking. Systems thinking are a framework of seeing interrelationships rather than seeing things, or seeing patterns of change rather than static snapshots, it views things as a whole. In the business context of systems thinking each department or section or function is directly connected to and influences the outcome of the next. This can be clearly understood by using the McKinseys 7s Model. The seven S being structure, systems, style, shared vision, strategy, skill and staff. McKinsey alludes that every ' $S$ ' depends on the other ' $S$ ', the failure of one affects the whole system (Peters and Waterman 1982). Of our interest in this case is the system. The system that an organisation adopts has a bearing on all the functions of the organisation. It is therefore important to have the right system that helps in the attainment of organisational objectives. Every component within the organisation should be linked to the system; however the actual system of HRIS has also dependent modules. This means that once information is put in the database it should be in a position to give various information which is linked to the systematic management of the human resource. Wrong storage of information will affect the whole system; this concept as well is linked to the systems thinking. Information obtained from HRIS database must be up to date, complete, flexible and easily accessible. A database is a collection of similar records with relationships between records. It can also be regarded as a collection of stored operational data used by the application system of some particular industries. Manzini and Grindley (1986) reveal that a fully integrated HRIS should have a database that should provide information on the following, health and safety, applicant tracking, benefits claims, individual biography, position control, succession planning, training and development, skills inventory, HR forecasting and planning, remunerations, affirmative action and position control.

In today's corporate world human resources have come to play a very critical role in a business. The belief that people working for a firm are one of its main assets and one of the decisive factors really can be proved. Aroson (2005) reiterates that, traditionally the use of computerised information system was manifested in bookkeeping and payroll a function determining its results is one that leaves little room for argument. In the information society, 
HR practitioners need to rethink how to deploy and mobilise the more valuable corporate resource. HR management practitioners are becoming strategic business partners in their organisations capable of contributing to the improvement of the organisations competitive advantage. HRIS merges human resource management with information technology to not only simplify the decision making process but also aid in complex negotiations that fall under the HR umbrella. The basic advantage of HRIS is not only computerised employee records and database but to maintain an up to date account of the decisions that have been made or that need to be made as part of HR management plan. HRIS provides the overall:

a. Management of employee information

b. Reporting and analysing of employee information

c. Company related documents such as employee handbooks, emergency evaluation procedures and safety guides

d. Benefits administration including enrolment, status changes and personal information updates

e. Complete integration with payroll and other company financial software and accounting systems

f. Applicant and resume.

Gallagher (2006) highlighted that the benefits of CHRIS fall into 2 categories, the first is the availability of up to date information in an intelligible and easily accessible forms throughout the organisation. Although, due the mandatory confidentiality certain restrictions will have to be imposed on access to information, the staff can expect to become more involved in the total work of the organisation. This should lead to greater job satisfaction and greater awareness of each person's contribution to the operation of the division. The second category of benefits of HRIS is the unnecessary duplication should be eliminated and repetitive time consuming procedures should be reduced. This will enable the division to provide a better, more professional service to the organisation. Some departments or sections will benefit more than others from computerisation.

The spacious array of HRM activities (e.g. planning, recruiting, selection and training) causes enormous responsibility on supervisors and managers. These embrace analysing jobs, planning, labour needs, selecting employees, managing compensation, communicating (which includes counselling and disciplining) and maintaining employee commitment. Lately the increasing pressure to support strategic objectives and the greater focus on shareholder value have led to changes in both job content and expectations of HR professionals (Ball 2000).

\section{Methodology}

The study used was mainly qualitative. Qualitative methods allow one to dig deep in the subject matter thus reaching people's inner feelings and attributes about the subject under study, Dooley (2003). The research was a case study Midlands State University in Zimbabwe. A case study design was used because the researchers wanted to understand the dynamics present within a single setting. ." A case study in its simplest form involves an investigator who makes a detailed examination of a single subject or phenomena, Borg and Gall (1989).

Purposive sampling was used to select participants in the HR department as the area of HRIS is well known to the HR staff. A total of six HR staff out of seven participated in the research.

Face to face structured interviews were carried out to gather information from all the participants due to its small sample size as well as participant observation. The interview questions were crafted basing on the objectives of the research paper. Each interview took at most 30 minutes. Both secondary and primary sources of data were used in this study. The primary source was gathered from the participants through interviews. The secondary sources of data were the HR records like personal documents and adverts.

\section{Presentation of Findings and Analysis}

When asked to respond on the areas that had on the functions that had been adopted into the HRIS 4 respondents highlighted that the HR function that had been incorporated in the system and this was the recruitment and selection process. The respondents went on to clearly outline that they had actually done electronic advertising through the use of the university web page; they had done away with manual advertising. Management from the HR department alluded that the HR department had ensured that all information pertaining to employees was electronically transferred. Employees can actually capture their personal details and their educational qualifications from their offices. They have a database that has information on each employee's details comprising of the name, date of birth, department, occupation and employment number. This was also supported by 2 respondents in the department who reiterated the same point. Management indicated that at least the university has made some progress in terms of communication that works hand in hand with the HR department. The university has a website "www.msu.ac.zw". This website allows for communication from within and outside the organisation. 
Information can be circulated fast to each and every employee within the university. Everyone is well informed on what is taking place within the university so much that ever employee is well updated. All the staff in the department alluded the department had moved from a manual way of advertising jobs to a more computerised way of advertising. It was also highlighted that they no longer incur costs in terms of printing advertisements for jobs or even communicating with other universities. Communication within and outside the university has been computerised. Each employee within the university has an email address and thus can actually communicate with everyone. 2 employees went on to explain that the department had done away with writing memos and reports manually. All these were now computerised as each employee has an email address.

It highlighted by the management that they used HRIS in terms of human resource planning also indicated that they had so far gathered information which they had acquired from Heads of departments in terms of staff the staff they have and their teaching loads on the teaching staff side. They have also gathered information on the non teaching staff. This was more of an audit to indicate the staff gap if any and the training gap. This information had already been computerised. Management indicated that this information helps in forecasting and planning of human resource.

It was pointed out that most of the activities in the running of the payroll were computerised although it not fully fledged as it is not linked to other departments like accounts. However the calculation of tax and other deductions were computerised. Mohite (2010) cites that making decisions have been cumbersome, traditionally employees used spread sheets to administer those compensations decisions. It must be noted that calculations results in cost reduction in the HR Function (DeSantis 1986). It was indicated that the payroll is very sensitive therefore computerising it would reduce some inconsistencies that can be very harmful to the organisation. Having a payroll database within the HRIS can be viewed as a critical component as remuneration is a very serious and sensitive issue. Payroll was one of the components in Human resource management that led to the evolution of HRIS. This is supported by Aroson (2005) who acknowledges that, traditionally the use of computerised information system was manifested in bookkeeping and payroll functions.

If one is to note what Manzini and Grindley (1998) highlighted as far as what the database should have the universities are still far. Manzini and Grindley identified 13 components that the database should have and from the data gathered the university that has tried to at least achieve it has only 4 I not less components in its database. This therefore reflects that the universities have not done much. A lot of work still has to be done in order to have a fully fledged CHRIS.

\subsection{Benefits of CHRIS}

The graph below shows the responses on the benefits of HRIS.

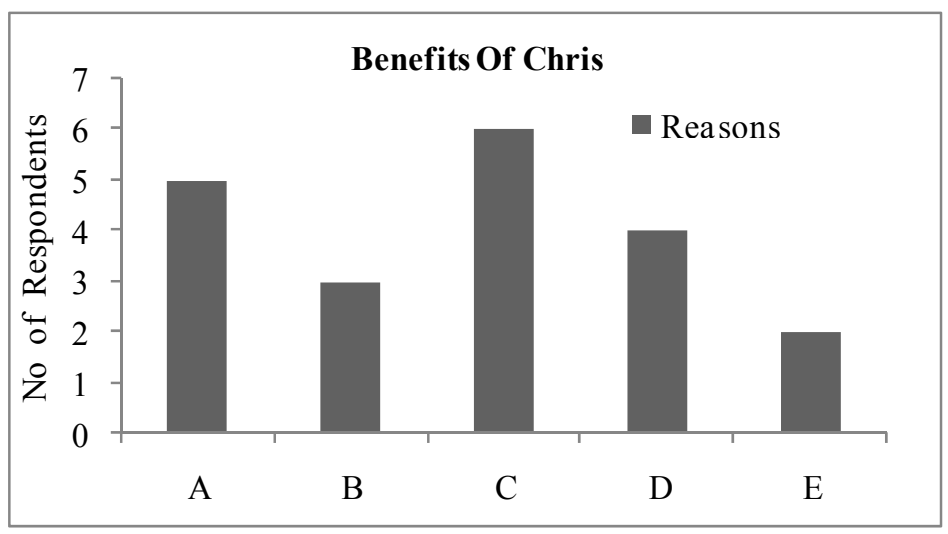

Figure 1. Benefits of CHRIS

Description: A -less paper work, B- improved communication, C-safe keeping of records, D- accuracy, E- allows strategic decision making

When asked on the benefits of using HRIS management noted that the university would easily communicate within and outside with other stakeholders. It was pointed out that the university can actually gain sustainable competitive advantage. Moreso it helped in the attraction and retention of qualified personnel. They gave an example that the web page can actually be used to attract and retain staff. According to Chanda (2008) the 
evaluation of HRIS has brought in value edition through knowledge management. It has opened up gates to knowledge available all over so that organizations capture it to obtain a competitive advantage, most successfully by the usage of the intranet. Armstrong (2006) reiterates that an intranet 'is an internal network that makes use of World Wide Web technology (browsers and servers amongst others to gather and disseminate information within the firm'. Intranets can be linked to the external internet, but are usually secured in a variety of ways so that only authorized users can access the information of the internal components. While it is quite easy to generate static extracts of HRIS data tables, queries, forms and reports for posting on an intranet, it is also quite feasible to establish live links between an intranet and a firm's HRIS. This allows real time collection and display of information. According to Chanda (2008), the boom in information technology and automation has enabled building teams to work which was earlier impossible. The HRIS revolution has paved the way to connect the teams worldwide without necessarily moving their desks thereby building virtual team.

It also allows the profession to be viewed as a more strategic partner that deals with major things rather than minor issues. It was highlighted that the role of HR will no longer be viewed as that of being administrative but to that of being decision makers and strategic thinkers. They indicated that instead of being seen as clerical people the HR practitioners would be given an upper hand and therefore uplifting the status of the profession. The role of $\mathrm{Hr}$ will no longer be seen as a peripheral function but a critical function that actually leads to the attainment of organisational goals. Employees actually acknowledge that through the use of HRIS there is more of efficiency and effectiveness. Employees can now spend much time dealing with majors and not minors. The HR practioneers can now actually set in strategic meetings and make strategic decisions that help in the attainment of organisational goals. This is also supported by the fact pointed out by Haines and Petit (1997) that HRIS relieves HR practitioners from many routine paper handling tasks. The human resource practioneers can hopefully develop a service orientation and participation role more fully in strategic decision making. Ulrich (1997) alludes that HRIS provides value to the organisation and improves HR professionals' own standing .HRIS provides management with strategic data not only in recruitment and selection but also in merging data into large scale corporate strategy.

Management highlighted that HRIS would assist in easy decision making. Decisions would be actually easy to make sine everything will at just a click of a button away. It was also pointed out that HRIS serves time. Time will not be waste moving from one department to another or checking files. Also everything can just be done under one roof. Much time would be left to deal with more strategic issues that are critical for the attainment of organisational objectives. According to Chanda (2008; 386), 'the basis for a good HR function and the decisions it takes depends upon the information it generates not only for itself but for all those who are involved in the business process. HRIS is meant for making better decisions and solving problems which were earlier difficult to do and therefore decisions taken after computerization brought in those changes like timely accurate and better solutions that gives higher customer satisfaction. With accurate data on hand, the HR department is able to extract accurate reports, deliver on all statutory requirements and aggregate information into apparently useful statistics and trend reports. However it should be noted that HRIS per se will not be a problem solver itself but would enable HR to function effectively by giving high quality information.' Moreover, computerized database of systems, policies and procedures has simplified the role played by HR.

It was also indicated that will be quite easy to keep records .Instead of keeping so many papers it will be quite easy to track records and avoid employing ghost workers. Record keeping will become easy and the university will not have to incur so many costs when it comes to stationer and other expenses.

\subsection{Challenges Faced in the Adoption of HRIS}

All the respondents highlighted that the major challenge they are facing in trying to adopt a fully integrated HRIS is that they are not really knowledgeable on how that can be done. They acknowledged that they just have generally knowledge when it comes to the inputting and managing personal information of employees but how to incorporate other functions like training and development and integrating that with other departments in the department is a challenge. It was also brought into consideration that they needed I.T experts in order to incorporate other HR variables in the system. Gallagher (2006) alludes that HRIS is an emerging concept that is associated with the evolution of strategic human resource management; this is also supported by Dave Ulrich's HR model. Dave Ulrich then supports points out in his model that since HRIS is an emerging concept HR practioneers should thus become administrative expects and moves away from the old way of conducting their activity. As pointed out by Thomas et al (2002), human resource information system are misunderstood and misapplied because of incomplete conceptualisation that do no focus on strategic vision of the central force. Most universities have failed to adopt the new technology because they do not have the knowledge or full understanding of what HRIS is all about. According to Kavangah (2006) HRIS is a system that keeps track of all employees and 
information about them. It is not just the general computerisation of employee information it also keeps track of employees in every aspect. It is usually done in a database or more often in a series of interrelated data bases. Therefore from the data acquired from the university it can be noted that employees just have a general knowledge of what it is.

The lack of consistent electricity supply is a huge challenge that was also pointed out. It was noted by five employees that the major challenge has to do with the major electricity cut offs in the country. This was said disrupts the way the department and the organisation operate since most on the information will be stored electronically. This was said was the other reason why the department was slow in trying to adopt a fully integrated HRIS. All ICT gadgets need electricity to function. Inadequate power generation and unreliable transmission and distribution capacity has a direct impact on ICT development strategies. This means there can be no meaningful revolution if there is no electricity. Mail servers, web servers, routers and switches all need electricity to operate. Zimbabwe just like any most African countries basically faces a number of hurdles in order to roll out effective computing technologies to the general population especially when it comes to power shortages ( ICT Guide,March 20 2009).

The lack of financial resource was another challenge that was noted by management. It was indicated that the University is still growing and trying to have infrastructure in place therefore their budget was much strained for the implementation of a fully integrated HRIS. It was indicated that in as much as they would loved to have it fully integrated money was the main limiting factor and that is why they are asking the process in phases but they hoped that in the near future it will be fully integrated. They also highlighted that the economy was still recovering and therefore things are not yet stable since the university heavily relies on state funds

\section{Recommendations}

The researcher recommends that there be regular training seminars and development of HR staff to keep abreast of new techniques, processes and materials. This should be the responsibility should be allocated to the deputy registrar's HR to ensure that each employee is trained all HR activities. There is need for great awareness of the benefits and advantage of HRIS in the university. In Zimbabwe there are experts who would workshops on HRIS and therefore the HR staff should be sent to those training programmes to become knowledgeable on how the system operates. The HR department must be innovative and not actually rely on IT staff only. With the little knowledge that they have with computers and knowledge that it is the researchers' belief that they can implement a fully fledged HRIS.

\section{References}

Armstrong, M. (2006). A Handbook of Human Resource Management Practice (10th ed.). London: Cambridge University Press.

Aroson, B. (2005). Decision Support Systems and Intelligence Support Systems. New Jersey: Prentice Hall.

Ball. (2000). The use of human resource management systems: A survey. Personnel Review, 677-693.

Borg \& Gall. (1989). Educational Research: An Introduction (8th ed). London: Longman.

Cascio, W. F. (2003). Managing Human Resources (6th Ed). New Dehli: Tata McGraw-Hill.

Chanda, C. (2008). Modelling Computation and Optimization. London: World Scientific Publishing.

Crane, P. D., \& Miner, J. B. (1995). Human Resource Management. New York: Harper Collins Publishers.

DeSanctis. (1986). Human Resource Information System: A current Assessment. MIS Quarterly, 15-26.

Dessler. (2008). Human Resource Management (11th edition). New Delhi: Pearson Education Inc.

Dooley. (2003). Social Research Methods. New Delhi: Prentice Hall.

Gallagher, M. (2006). Computers and Personnel Management. London: Heinemann.

Haines, \& Peitt. (1997). Human Resource Management: Contemporary Issues, Challenges and Opportunities. USA: Information Age Publication.

Kavanagh, M. J. (2006). Human Resource Information Systems: Development and application. Kent: Boston.

Kenton, \& Yarnall. (2005). HR-the Business Partner: Shaping a new direction. Oxford: Elsevier Butterworth Heinemann.

Manzini, A., \& Grindley. (1986). Integrating human Resources and Strategic Business Planning. Washington D.C: Amacon. 
Mayhew, R. (2011). The Business Today. India: Sanci Publishing.

Mohite. (2010). Impact of Managing Personnel Records in an Electronic Environment (HRIS) on Business Organizations and Related Problems. Kamlapur: Sinhgad Institute of Business Management.

Peters \& Waterman. (1982). In Search of Excellence. Harper \& Row: New York.

Thomas, S. A. (2002). Evaluation Practice Reconsidered. New York: Lang Publishers.

Toresa \& Toress. (1998). Information Technology at its best. Midow.

Ulrich, D. (1997). Human Resource Champions. Boston: Harvard University Press. 